
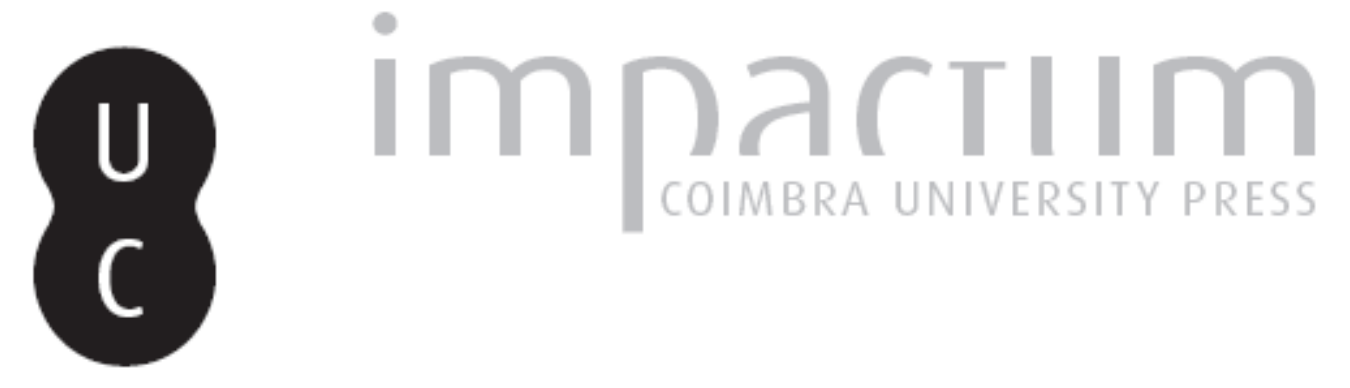

\title{
A propósito das inscrições de Sarzedas e Sertã
}

Autor(es): D'Encarnação, José; Leitão, Manuel

Publicado por: Imprensa da Universidade de Coimbra

URL persistente:

URI:http://hdl.handle.net/10316.2/45704

DOI:

DOI:https://dx.doi.org/10.14195/1647-8657_21_3

Accessed : $\quad$ 26-Apr-2023 11:04:03

A navegação consulta e descarregamento dos títulos inseridos nas Bibliotecas Digitais UC Digitalis, UC Pombalina e UC Impactum, pressupõem a aceitação plena e sem reservas dos Termos e Condições de Uso destas Bibliotecas Digitais, disponíveis em https://digitalis.uc.pt/pt-pt/termos.

Conforme exposto nos referidos Termos e Condições de Uso, o descarregamento de títulos de acesso restrito requer uma licença válida de autorização devendo o utilizador aceder ao(s) documento(s) a partir de um endereço de IP da instituição detentora da supramencionada licença.

Ao utilizador é apenas permitido o descarregamento para uso pessoal, pelo que o emprego do(s) título(s) descarregado(s) para outro fim, designadamente comercial, carece de autorização do respetivo autor ou editor da obra.

Na medida em que todas as obras da UC Digitalis se encontram protegidas pelo Código do Direito de Autor e Direitos Conexos e demais legislação aplicável, toda a cópia, parcial ou total, deste documento, nos casos em que é legalmente admitida, deverá conter ou fazer-se acompanhar por este aviso.

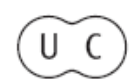


FACULDADE DE LETRAS

INSTITUTO DE ARQUEOLOGIA

\section{CONIMBRIGA}

VOLUMEXXI

UNIVERSIDADE DE COIMBRA

1982 
JOSÉ D'ENCARNAÇÀ O

Assistente da Faculdade de Letras de Coimbra

MANUEL LEITÃo

Funcionário da Câmara Municipal de Castelo Branco

A PROPÓSITO DAS INSCRIÇÕES DE SARZEDAS E SERTÃ

Conimbriga, XXI (1982), p. 127-133

RESU Mo: Uma inscrição proveniente de Sarzedas, hoje desaparecida, foi interpretada como a prova da restauração da povoação por uma filha de Viriato. Reconstitui-se, a partir dessa interpretação fantasista, o epitáfio de Veratia, Veratii filia, que deverá passar a figurar no corpus das inscrições peninsulares.

$O$ texto da Sertã, também desaparecido, interpretado de forma totalmente irrealista, não apresenta dados que permitam considerá-lo romano.

RÉSU MÉ: Une inscription trouvée à Sarzedas (Castelo Branco, conventus Scallabitanus), aujourd'hui perdue, a été interprétée comme la preuve de la restauration du village par une fille de Viriatus, chef de guerre des Lusitaniens. Les auteurs reconstituent ici, à partir de cette interprétation fantaisiste, l'épitaphe de Veratia, Veratii filia, qui doit prendre place dans le corpus des inscritpions de la Péninsule Ibérique.

Un texte de Sertã (conventus Scallabitanus), disparu lui aussi, lu d'une façon irréaliste, n'est pas susceptible de reconstitution; son caractere romain est même très douteux. 
(Página deixada propositadamente em branco) 


\section{A PROPÒSITO DAS INSCRIÇÕES DE SARZEDAS E SERTÂ*}

Sempre a epigrafia se prestou para outorgar antiguidade a terras cuja origem se perdeu na noite dos tempos. A fantasia dos autores, a ignorância das regras epigráficas e a vontade de atribuir aos Romanos tudo quanto fosse pedra lavrada - em muito contribuíram nâo só para proteger um rico património mas também para se forjarem lendas piedosas repetidas de geração em geração sem que alguém sobre elas se debruce com verdadeiro espírito científico.

Descobrindo siglas onde existem palavras, descobrindo palavras onde existem siglas - o mais simples epitáfio romano pode transformar-se em imponente inscrição comemorativa. Assim aconteceu com as duas inscrições perdidas, de que vamos falar.

\section{O texto de $S$ ar zedas}

Por volta de 1880, quando se lavrava um olival junto da matriz de Sarzedas, encontrou-se uma placa rectangular em xisto, cujas dimensões se desconhecem. A primeira interpretação do texto foi dada pelo então pároco, P.e Manuel António da Silva, que leu:

VERATIA VERATI FILIA REEDIFICAVIT HOC OPPIDVM SARZEDENSAE ET CONCESSIT EI PREVILEGIVM CIVITATIS.

(*) Comunicação apresentada às I Jornadas Arqueológicas da Beira Baixa (Castelo Branco, Abril 1979). 
Mais ou menos à letra, o letreiro quereria, pois, dizer:

«Viriata, filha de Viriato, reedificou este castelo de Sarzedas e concedeu-lhe o privilégio de cidade».

Os erros de concordância e de escrita eram tidos, como habitualmente, à conta da pouca cultura do lapicida ou das gentes de antanho.

Assim interpretada, a inscrição assumia importância relevante, porquanto fazia remontar a origem da povoação ao tempo das gloriosas lutas entre Romanos e Lusitanos, atribuindo-lhe como fundadora nada menos do que uma filha de Viriato, o célebre, pois que de outro não se podia tratar.

Mas a pedra desapareceu — acabou, partida em pedaços, incorporada num forno de cozer pão.

Entretanto, para além de inúmera correspondência a seu respeito trocada entre personalidades da terra, insertas num artigo de arqueologia publicado nas págs. 3 e 6 do jornal «Terra da Beira» (1 de Agosto de 1930), outros trabalhos se lhe referiram, não pondo, contudo, em dúvida o seu conteúdo: Couceiro de Albuquerque, $O$ Castelo de Sarzedas, «Estudos de Castelo Branco», n. ${ }^{\circ}$, Janeiro de 1963, p. 69-73; Francisco Duarte de Miranda e Godofredo Alberto dos Santos Ferreira, Documentos e notas para a monografia de Sarzedas, separata de «Estudos de Castelo Branco», 1966, p. 17-37.

No entanto, já em 1910, no vol. XV d’«0 Archeologo Português», p. 323, Leite de Vasconcelos lançara luz sobre o assunto, considerando o texto autêntico mas mal interpretado, mormente através do desdobramento de siglas inexistentes. Falta-nos, infelizmente, um desenho do original; contudo, a versão de Leite de Vasconcelos (desconhecida dos citados autores) é verosímil, pelo que a seguimos na generalidade.

Considerando a inscrição um epitáfio, teríamos que nela incluir a identidade da defunta, uma fórmula funerária, a identificação do dedicante e a fórmula dedicatória.

A identificação da defunta foi bem lida: VERATIA VERATI(i) $\mathrm{F}$ (ilia). $\mathrm{O}$ antropònimo Veratius é conhecido doutras inscrições 
peninsulares G) e a forma de identificação usando apenas os cognomes é por demais corrente na região. $\mathrm{O}$ vocábulo filia estaria em sigla, mas o P. e Manuel da Silva não tinha obrigação de saber as regras de transcrição: aqui pôs por extenso o que estava em sigla, mais adiante considera no texto formas verbais que achou por bem subentender.

Desta forma, as siglas H. S. E. - H(ic) S(ita) $E($ st $)$ - devem ter-se transformdo em $H$ (oc oppidum) S(arzedensae) E(t).

$\mathrm{E}$ a fórmula final $\mathrm{P}$ (onendum) $\mathrm{C}$ (uravit) foi interpretada $\mathrm{P}$ (rivilegium) $\mathrm{G}$ (ivitatis).

Resta, pois, a identificação do dedicante. Poderá ter sido escrito o seu nome - com cujas letras se leu Sarzedensae et concessit ei - ou, mais verosimilmente, apenas o grau de parentesco MATER, PATER. Inclinamo-nos para esta segunda hipótese, descobrindo-o assim na versão do P. e Manuel da Silva :(concessi) TER - do $\mathrm{R}$ só teria $\mathrm{v}^{\wedge}$ sto a haste vertical. Leite de Vasconcelos sugere que EI poderia estar no monumento - julgamos que não: o emprego deste dativo é muito raro na epigrafia da região. A invenção do verbo concessit não teve certamente em conta as letras do monumento, que, aliás, poderiam estar levemente obliteradas (se aceitarmos que do $\mathrm{R}$ estava visível uma parte).

Por conseguinte, estamos com imensa probabilidade perante uma inscrição autêntica, que se deverá passar a incluir nos católogos epigráficos e que se poderá reconstituir assim:

VERATIA VERATI(i) F (ilia) / H (ic) . S(ita) . E(st) / [MA vel PAjTER . P \{onendum) . G (uravit).

Aqui jaz Verácia, filha de Verácio. A mãe (ou o pai) mandou colocar (esta memória).

Desconhecemos as dimensões do monumento, pelo que a transliteração apresentada é hipotética.

Pelo formulário, é texto datável do séc. i da nossa era.

(l) CIL II, 3433 e 4972105. M. Lourdes Albertos, «Emerita», XXXIII, 1965 , p. 133, s. V. nVerati(us)».

Conimbriga, 21 (1982), 127-133 


\section{O texto da Sertã}

O texto da Sertã é mais sibilino.

Encontrado também por volta de 1880 na povoação de Perna do Galego, freguesia da Ermida, concelho da Sertã — anda hoje perdido. Mário Saa $\left(^{2}\right)$ escreve que ele «se acha guardado num pequeno museu da Sertã», informação qe não se pode confirmar, sendo certo que já o autor do citado artigo de «Terra da Beira» lhe perdera o rasto. Soubémos que uma «pedra com letras» fora levada para Lisboa: tratar-se-á da mesma?

Pelo aspecto gráfico com que a inscrição é aí apresentada - e somente aí a vimos em letra de forma - parece-nos a metade direita duma placa. Mas não só nada nos garante que seja romana como consideramos puramente fantasiosa a interpretação do fragmento e - muito mais ainda! — a da metade que falta, A reconstituição é da autoria do Major Santos Ferreira e foi transmitida ao referido autor por António Couceiro d'Albuquerque. Reza assim $\left(^{3}\right)$ :

[VT SINT] STATVAE / [C(onstantini) . GJALLI / [ROM(anae) GOMPJAR REI NIL / [LIC]ET / 5[...] [MAXVJMO CO(n)S(ule) $\mathrm{AE}$ (dilibus) $\quad I \quad[\ldots] \quad$ [ET] IVBA EGIT(aniensis) / [VIRI NOTA]BILIORVM / [PROPTER] SVMMA[E] / [POTESTATIS] NOMI$\mathrm{NE}[\mathrm{M}] /{ }^{10}[\mathrm{DE}$ SEN (atus) SENT(mím)] ST AT ITA.

$\mathrm{Na}$ 1. 7, a palavra VIRI está na transcrição paleogràfica mas não foi interpretada por lapso - o autor deve tê-la entendido como VIR(orwm) - dos varões. A última letra das 1.8 e 9 ou foram reconstituídas ou figuram no texto originai fora do campo epigráfico.

A tradução apresentada é como segue:

«Não é permitido haver estátuas de Constantino Gallo, comparte no Impèrio Romano. Sendo cónsul (...) Máximo e

(2) As grandes vias da Lusitânia, Lisboa, III, 1960, p. 282.

(3) Damos a transcrição segundo as actuais regras epigráficas, com base no texto apresentado na «Terra da Beira».

Conimbriga, 21 (1982), 127-133 
edis (...) e Juba, egitanienses dos mais notáveis. Em razão do prestígio do Poder Supremo. Por sentença do Senado assim está resolvido».

Logicamente que tudo isto é inaceitável e nem chegamos a perceber como Mário Saa possa falar de «monumento, que parece de ordem vial, respeitante ao mauritano Juba, na época romana».

De facto só reencontrando a pedra se poderão tirar conclusões válidas. Desde já se avança, porém, numa recusa total das mencionadas interpretações. Não se nos afigura possível tratar-se de um marco, pois é difícil partir um miliàrio ao meio. Por outro lado, palavras como summa, nomine, são frequentes em textos bíblicos: não será preferentemente nessa direcção que se deverá caminhar? Julgamos que sim. Entretanto, é texto a não figurar (mesmo dubitativamente) em catálogos de epigrafia romana. 